\title{
Interaction of inhibitory and facilitatory effects of conditioning trials on long-term memory formation
}

\author{
Shouhei Hosono, ${ }^{1,2}$ Yukihisa Matsumoto, ${ }^{3,4}$ and Makoto Mizunami ${ }^{3}$ \\ ${ }^{1}$ Graduate School of Life Science, Hokkaido University, Sapporo 060-0810, Japan; ${ }^{2}$ Graduate School of Agriculture, Tamagawa \\ University, Machida 194-8610, Japan; ${ }^{3}$ Faculty of Science, Hokkaido University, Sapporo 060-0810, Japan; ${ }^{4}$ Faculty of Liberal \\ Arts, Tokyo Medical and Dental University, Ichikawa 272-0827, Japan
}

\begin{abstract}
Animals learn through experience and consolidate the memories into long-time storage. Conditioning parameters to induce protein synthesis-dependent long-term memory (LTM) have been the subject of extensive studies in many animals. Here we found a case in which a conditioning trial inhibits or facilitates LTM formation depending on the intervals from preceding trials. We studied the effects of conditioning parameters on LTM formation in olfactory conditioning of maxillary-palpi extension response with sucrose reward in the cockroach Periplaneta americana. We found, at first, that translation- and transcription-dependent LTM forms $1 \mathrm{~h}$ after training, the fastest so far reported in insects. Second, we observed that multipletrial training with an intertrial interval (ITI) of 20 or $30 \mathrm{sec}$, often called massed training, is more effective than spaced training for LTM formation, an observation that differs from the results of most studies in other animals. Third, we found that a conditioning trial inhibits LTM formation when the intervals from preceding trials were in the range of 10-16 min. This inhibitory effect is pairing-specific and is not due to decreased motivation for learning (overtraining effect). To our knowledge, no similar inhibition of LTM formation by a conditioning trial has been reported in any animals. We propose a model to account for the effects of trial number and ITIs on LTM formation. Olfactory conditioning in cockroaches should provide pertinent materials in which to study neuronal and molecular mechanisms underlying the inhibitory and facilitatory processes for LTM formation.
\end{abstract}

[Supplemental material is available for this article.]

Animals learn from experience and consolidate the memory into long-term storage. Classical conditioning is one of the basic forms of associative learning in many vertebrates and invertebrates, and investigation of conditioning parameters for acquisition and retention of long-term memory (LTM) has been a fundamental issue in the study of learning and memory (Dudai 2012; Dudai and Morris 2013; Kandel et al. 2014). It has been shown that multiple trials are more effective than a single trial for inducing protein synthesis-dependent LTM and that spaced training with a longtime interval (typically over $1 \mathrm{~min}$ ) is more effective than massed training with short intervals for inducing LTM in many studies in vertebrates and invertebrates (Sutton et al. 2002; Cepeda et al. 2006; Philips et al. 2007; Sunsay and Bouton 2008) including insects (honeybees: Gerber et al. 1998; Menzel et al. 2001; fruit flies: Tully et al. 1994; Margulies et al. 2005; Pagani et al. 2009; Akalal et al. 2010; crickets: Matsumoto and Mizunami 2002; Matsumoto et al. 2006). Here we report a case that appears to be an exception to the latter rule.

In this study, we investigated stimulus parameters to determine olfactory long-term memory formation in the cockroach, Periplaneta americana. Olfactory learning capabilities of cockroaches have been well documented in studies using an operant conditioning procedure (Sakura and Mizunami 2001; Sakura et al. 2002) and a classical conditioning procedure (Watanabe et al. 2003, 2008; Watanabe and Mizunami 2006, 2007). In addition, olfactory receptor neurons and olfactory interneurons in the brain have been anatomically and physiologically characterized in some detail in the cockroach (Boeckh and Ernst 1987;

\section{Corresponding author: mizunami@sci.hokudai.ac.jp}

Article is online at http://www.learnmem.org/cgi/doi/10.1101//m.043513. 116.
Watanabe et al. 2010; Nishino et al. 2011, 2012, 2015), and experiments with local microinjection of acetylcholine receptor antagonist suggest that the mushroom body plays critical roles in olfactory learning (Watanabe et al. 2011). However, stimulus parameters to determine acquisition and retention of long-term memory have not been characterized.

In this study, we first developed a procedure for olfactory conditioning of maxillary-palpi extension response (MER) in cockroaches. We recently showed that crickets extend and vibrate their maxillary palpi in response to presentation of water to the antennae or the mouth and that they also exhibit the same responses when an odor conditioned with water is presented to the antennae (Matsumoto et al. 2015; Awata et al. 2016), and here we show that cockroaches exhibit the same responses to presentation of sucrose solution or sucrose-associated odors. By using MER, we investigated the effects of the number of conditioning trials and the intervals between the trials for formation (consolidation) of long-term memory (LTM), and we found some unique features of stimulus parameters for formation of LTM. Notably, we found that a conditioning trial can inhibit or facilitate LTM formation depending on the timing from preceding trials, an observation that, to our knowledge, has not been reported in any animals.

C 2016 Hosono et al. This article is distributed exclusively by Cold Spring Harbor Laboratory Press for the first 12 months after the full-issue publication date (see http://learnmem.cshlp.org/site/misc/terms.xhtml). After 12 months, it is available under a Creative Commons License (AttributionNonCommercial 4.0 International), as described at http://creativecommons. org/licenses/by-nc/4.0/. 


\section{Results}

\section{Olfactory conditioning of MER in cockroaches}

We first established a procedure for olfactory conditioning of MER in cockroaches. When a cockroach is stationary, the maxillary palpi are held beneath the mouthpart. When a drop of sucrose solution was placed on the antennae or a filter paper soaked with essence of food odor was presented near the antennae, the cockroach extended and vigorously swung its maxillary palpi (Fig. 1A; Supplemental Movie 1), which we refer to as MER. This response was immediately followed by upward and forward extension of the mouth, vigorous swinging of antennae, and forward locomotory movement. Thus, MER is an initial part of a sequence of exploratory behavior.

We investigated whether repeated pairing of an odor with sucrose reward (Fig. 1B) leads to a pairing-specific increase in the probability of MER to the odor. One group of cockroaches received five pairing trials with a 7-min intertrial interval (ITI) (paired group, Fig. 1C). The percentage of MERs during a 3-sec period of odor presentation was scored. The group exhibited a significant increase in percentage of MERs to the paired odor (CS) with an increase in the number of trials (Fig. 2A, Cochran's Q test: $n=54$, $\left.P=4.70 \times 10^{-15}, \chi^{2}=73.24\right)$. A control group received unpaired presentations of an odor (CS) and a sucrose solution (US) for five times each with a 3.5-min ITI (unpaired group). Another two control groups received presentation of an odor CS alone or sucrose US alone for five times (odor-only group or sucrose-only group) (Fig. 1C). In the unpaired group and odor-only group, percentages of MERs during a 3-sec period of odor presentation were scored. In the sucrose-only group, a filter paper containing no odor essence
A

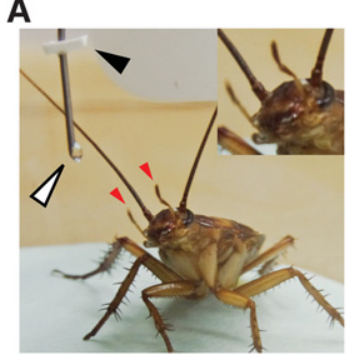

B

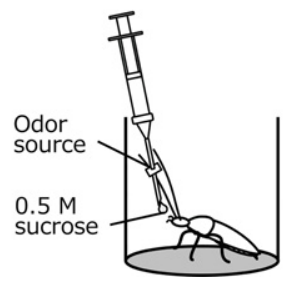

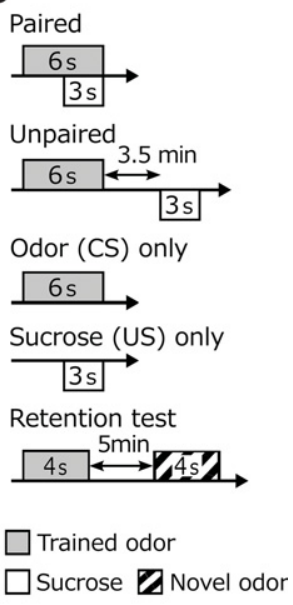

Figure 1. Experimental procedures. (A) A photograph of maxillarypalpi extension response (MER) of a cockroach, Periplaneta americana, to presentation of an odor. Red arrowheads indicate the maxillary palpi. The black arrowhead indicates a filter paper soaked with odor essence and the white arrowhead indicates a drop of sucrose solution. (B) A schematic illustration of a conditioning trial to associate an odor (CS) with 0.5 $M$ sucrose solution (US). (C) Conditioning and control procedures. Groups of cockroaches were subjected to paired or unpaired presentation of CS and US (paired or unpaired groups) or presentation of CS or US alone (odor-only and sucrose-only groups). The paired group received 6-sec CS presentation and subsequent 3-sec US presentation with a 3 -sec delay from the CS onset. The unpaired group received 6-sec CS presentation and subsequent 3-sec US presentation with a 3.5-min interval. The odor-only group and sucrose-only group received 6-sec odor presentation and 3-sec presentation of sucrose solution, respectively. The retention test consisted of 4-sec CS presentation and 4-sec presentation of a novel odor with a 5-min interval. was presented near the antennae for $3 \mathrm{sec}$ before sucrose presentation, and the percentage of MERs during the 3-sec period was determined. The unpaired group exhibited a significant increase in the percentage of MERs with progress of training, but the odoronly group and sucrose-only group did not (Fig. 2A, statistical results shown in legends). A small increase in the MERs in the unpaired group may reflect an unspecific sensitizing effect. Statistical comparisons among groups showed that the percentage of MERs in the paired group did not differ from those in control groups in the first trial (before presentation of a US and thus before the first pairing), but the percentage of MERs in the paired group was significantly greater in the fifth trial (i.e., after four trials). We thus conclude that the increase in MERs to the paired odor is pairing-specific and is not due to a nonassociative sensitizing effect.

In the 1-d retention test, the paired group exhibited a significantly higher percentage of MERs to the odor used in training (trained odor) than to a novel odor not used in training (Fig. 2B). In contrast, the unpaired group and the odor-only group exhibited no significant difference in percentages of MERs to the trained odor and to a novel odor. In the sucrose-only group, there was no significant difference in percentages of MERs to two novel odors (rose and orange odors). We thus conclude that five-trial conditioning with a 7-min ITI is sufficient to induce acquisition and 1-d retention of CS-specific memory. The percentage of MERs to the trained odor in the unpaired group appeared to be very low, but it did not significantly differ from that in the odor only group.

\section{Effects of five-trial conditioning with different ITIs on acquisition and 1-d memory retention}

A major aim of this study was to clarify the effects of number of trials and ITI on formation of long-term memory. We first studied the effects of five-trial conditioning with different ITIs. Seven groups of cockroaches received five-trial conditioning with an ITI of $20 \mathrm{sec}, 30 \mathrm{sec}, 2 \mathrm{~min}, 5 \mathrm{~min}, 7 \mathrm{~min}, 10 \mathrm{~min}$, or $15 \mathrm{~min}$. All of the groups exhibited significant increases in percentages of MERs to the CS with increase in the number of trials (Fig. 2C). In the 10-min ITI group, however, the level of acquisition was low. Comparison among groups showed that percentages of MERs at the fifth trial in the 20-sec, 30-sec, 2-min, and 7-min ITI groups, but not in the 5- and 15-min ITI groups, were significantly higher than that in the 10-min ITI group.

In the 1-d retention test, all groups except for the 5-min ITI group exhibited significantly higher percentages of MERs to the CS than to a novel odor (Fig. 2D), indicating that the memory is CS-specific. We thus conclude that five-trial conditioning with ITIs of $20 \mathrm{sec}, 30 \mathrm{sec}, 2 \mathrm{~min}, 7 \mathrm{~min}, 10 \mathrm{~min}$, and $15 \mathrm{~min}$ leads to 1-d retention but that five-trial conditioning with a 5-min ITI does not. The absence of 1-d retention of CS-specific memory with this specific stimulus parameter was the subject of our experiments described in a later section. Comparison of percentages of MERs at the fifth trial and in the 1-d retention test showed that they significantly decreased in the 20-sec and 2-min ITI groups but not in other groups, obviously due to a sensitization effect adding to the acquisition performance in the short ITI groups.

\section{Dissection of translation- and transcription-dependent long-term memory from earlier memories}

In various systems of learning in many animals, memory after training can be divided into several phases with different time courses and with different underlying biochemical or cellular processes, such as amnesia-sensitive short-term memory (STM), amnesia-resistant mid-term memory (MTM), and protein 
A Acquisition

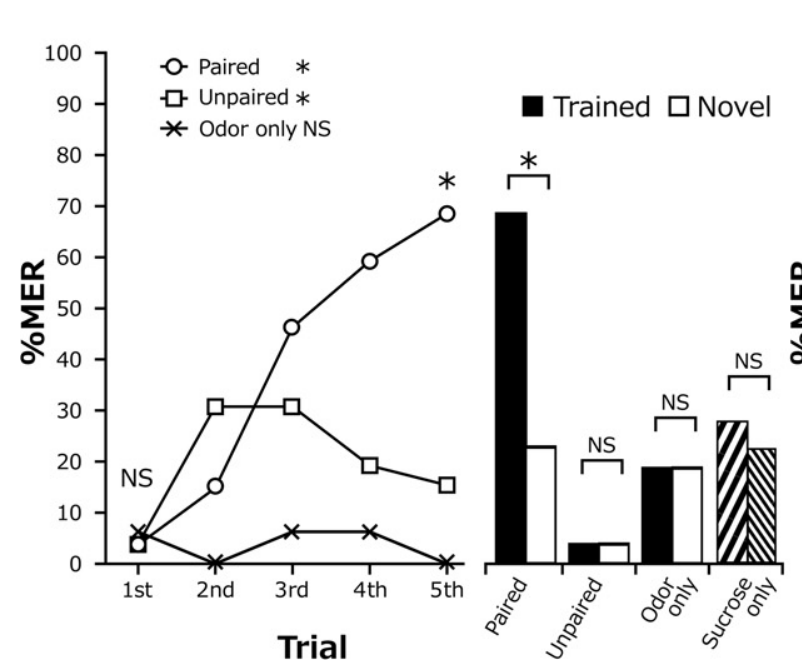

C Acquisition

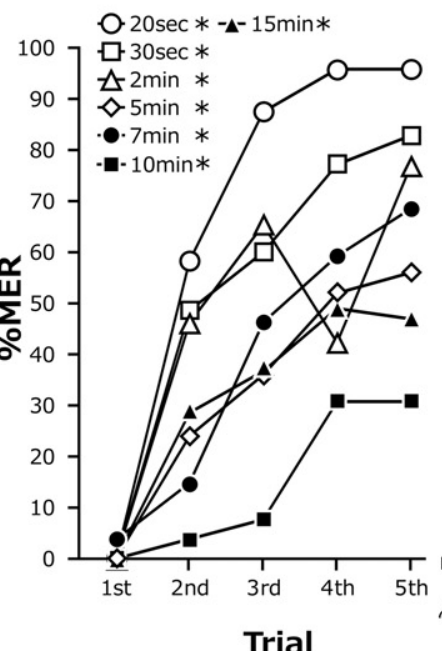

D 1-day Retention CS $\square$ Novel

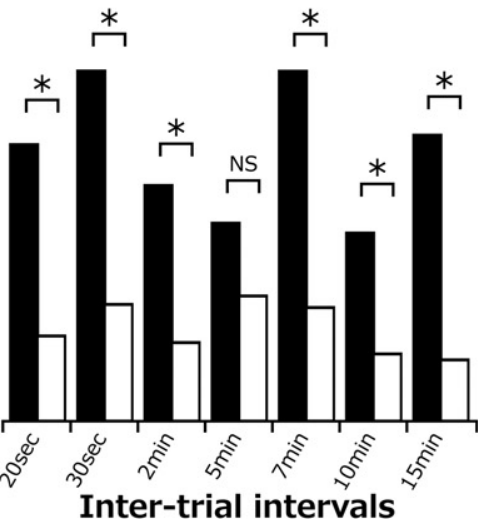

Figure 2. Evaluation of the pairing-specific effect $(A, B)$ and the effect of ITIs $(C, D)$ in five-trial conditioning. $(A)$ Acquisition performances of the paired group, unpaired group, odor-only group, and sucrose-only group in five-trial conditioning with 7-min ITIs. Percentages of MERs to the odor are shown for the former three groups. The paired and unpaired groups exhibited significant increases in percentages of MERs with increase in the number of trials, but the odor-only group did not (Cochran's $Q$ test: unpaired: $n=26, P=0.046, \chi^{2}=9.67$; odor only: $n=16, P=0.76, \chi^{2}=2$ ). Percentages of MERs did not significantly differ among the groups in the first trial (LR test: $P=0.91$, deviance $=0.18, \mathrm{df}=2)$ but significantly differed in the fifth trial $(\mathrm{LR}$ test: $P=$ $1.0 \times 10^{-9}$, deviance $=41.43, \mathrm{df}=2$; Fisher's exact test: paired group vs. odor-only group: $P=4.7 \times 10^{-7}$, odds ratio $=$ Inf.; unpaired vs. odor only: $P=0.27$, odds ratio $=$ Inf.). $(B)$ One-day retention after five-trial conditioning with 7-min ITIs. Percentages of MERs to the CS (black bar) and to a novel odor (white bar) were compared in the paired, unpaired, and odor-only groups (McNemar's test: paired group; $P=1.63 \times 10^{-5}, \chi^{2}=18.58 ;$ unpaired, $P=1, \chi^{2}=0$; odor only, $P=1, \chi^{2}=0$ ). In the sucrose-only group, percentages of MERs to two novel odors, rose (left down shaded bar) and orange (right down shaded bar) odors, were compared (McNemar's test: $P=1, \chi^{2}=0$ ). The percentage of MERs to the trained odor in the paired group, but not in the odor-only group, was significantly higher than that in the unpaired group ( $\mathrm{LR}$ test: $P=2.23 \times 10^{-9}$, deviance $=39.84$, df $=2$; Fisher's exact test: paired vs. unpaired: $P=2.24 \times 10^{-8}$, odds ratio $=0.019$; unpaired vs. odor only: $P=0.15$, odds ratio $\left.=0.18\right)$. $(C)$ Acquisition performance after five-trial conditioning with different ITIs. Percentage of MERs to the CS increased with the progress of training in all groups (Cochran's $Q$ test: $20 \mathrm{sec}, n=24, P=0.00018, \chi^{2}=14 ; 30 \mathrm{sec}, n=35, P=3.74 \times 10^{-5}, \chi^{2}=17 ; 2 \mathrm{~min}, n=24, P=0.00053, \chi^{2}=12 ; 5 \mathrm{~min}, n=49, P=4.16 \times$ $10^{-8}, \chi^{2}=40.09 ; 7 \mathrm{~min}, n=54, P=4.70 \times 10^{-15}, \chi^{2}=73.24 ; 10 \mathrm{~min}, n=38, P=1.78 \times 10^{-5}, \chi^{2}=27.23 ; 15 \mathrm{~min}, n=25, P=2.07 \times 10^{-5}, \chi^{2}=$ 26.92). Percentage of MERs in the fifth trial of the 10-min group was compared with those of other groups (LR test: $P=1.14 \times 10^{-7}$, deviance $=43.05$, $\mathrm{df}=6$; Fisher's exact test: $20 \mathrm{sec}$ vs. $10 \mathrm{~min}: P=1.37 \times 10^{-6}$, odds ratio $=14.01,30 \mathrm{sec}$ vs. $10 \mathrm{~min}: P=0.00012$, odds ratio $=14.01 ; 2 \mathrm{~min}$ vs. 10 min: $P=0.0019$, odds ratio $=7.16 ; 5$ min vs. 10 min: $P=0.23$, odds ratio $=1.84 ; 7$ min vs. 10 min: $P=0.0018$, odds ratio $=4.79 ; 15$ min vs. 10 min: $P=$ 0.092). (D) One-day retention performance after five-trial conditioning with different ITIs. Percentage of MERs to the CS was significantly greater than that to a novel odor in all groups except for the 5 -min ITI group (McNemar's test; $20 \mathrm{sec}, n=24, P=0.016, x^{2}=5.82 ; 30 \mathrm{sec}, n=35, P=0.00041, \chi^{2}=$ $12.5 ; 2 \min , n=26, P=0.027, \chi^{2}=4.9 ; 5 \mathrm{~min}, n=49, P=0.07, \chi^{2}=3.27 ; 7 \mathrm{~min}, n=54, P=1.63 \times 10^{-5}, \chi^{2}=18.58 ; 10 \mathrm{~min}, n=38, P=0.04$, $\left.\chi^{2}=4.27 ; 15 \mathrm{~min}, n=25, P=0.0055, \chi^{2}=7.69\right)$. Percentages of MERs to the CS significantly decreased from the fifth trial to the $1-\mathrm{d}$ retention test in the 20 -sec and 2 -min groups but not in other groups (McNemar test: 20 sec: $P=0.0094, \chi^{2}=6.75 ; 30$ sec: $P=1, \chi^{2}=0 ; 2$ min: $P=0.0027$, $\chi^{2}=4.9 ; 5$ min: $P=0.48, \chi^{2}=0.5 ; 7$ min: $P=1, \chi^{2}=0 ; 10$ min: $P=0.72, \chi^{2}=0.13 ; 15$ min: $\left.P=1, \chi^{2}=0\right)(*) P<0.05, N S: P>0.05$.

synthesis-dependent LTM (Tully et al. 1994; Tiunova et al. 1998; Menzel 1999). We studied the effects of actinomycin (Act-D, a transcription inhibitor, dissolved in $1 \%$ DMSO) and cycloheximide (protein synthesis inhibitor) on acquisition and 30-min, 1-h, and 1-d retention. We also tested the effect of L-NAME (NO synthesis inhibitor), which inhibits the formation of protein synthesis (translation)-dependent LTM in cockroaches (Matsumoto et al. 2013). Four groups of cockroaches were injected with saline or saline containing cycloheximide, actinomycin D, L-NAME, or DMSO (saline, CHX, Act-D, L-NAME, and D-saline groups) at $30 \mathrm{~min}$ before five-trial conditioning with 30 -sec ITIs and then received a retention test at $30 \mathrm{~min}, 1 \mathrm{~h}$, or $1 \mathrm{~d}$ after conditioning. The doses of the drugs were determined on the basis of results of our previous study (Matsumoto et al. 2013).

All of the groups exhibited significant increases in percentages of MERs to the CS with progress of training (Fig. 3A). The levels of acquisition in the Act-D group and D-saline group appeared to be slightly lower, but no statistically significant difference was found among the groups at the fifth trial. In the 30-min retention test, all of the groups exhibited significantly greater responses to the CS than to the novel odor (Fig. 3B). In the 1 -h and 1-d reten- tion tests, the control group injected with saline or saline containing DMSO (D-saline) exhibited a greater response to the CS than to a novel odor, indicating retention of CS-specific memory, but the CHX, L-NAME, and Act-D groups exhibited no significantly greater percentages of MERs to the CS than to the novel odor (Fig. 3C,D), indicating no retention of CS-specific memory. The results show, at first, that translation- and transcription-dependent LTM is established only $1 \mathrm{~h}$ after training. To our knowledge, this is the fastest formation of LTM so far reported in insects: it has been reported that protein synthesis-dependent olfactory LTM is fully developed $8 \mathrm{~h}$ after training in crickets (Matsumoto et al. 2003), $24 \mathrm{~h}$ after training in fruit flies (Tully et al. 1994; Margulies et al. 2005), and $3 \mathrm{~d}$ after training in honeybees (Menzel 1999; Matsumoto et al. 2014). Second, "massed" pairing trials with a 30 -sec ITI lead to formation of protein synthesisdependent LTM formation in cockroaches: This is in contrast to results of previous studies showing that "spaced" pairing trials with ITIs of at least $1 \mathrm{~min}$ are necessary for formation of protein synthesis-dependent LTM in other species of insects (fruit flies, Tully et al. 1994; honeybees, Menzel et al. 2001; crickets, Matsumoto and Mizunami 2002). 

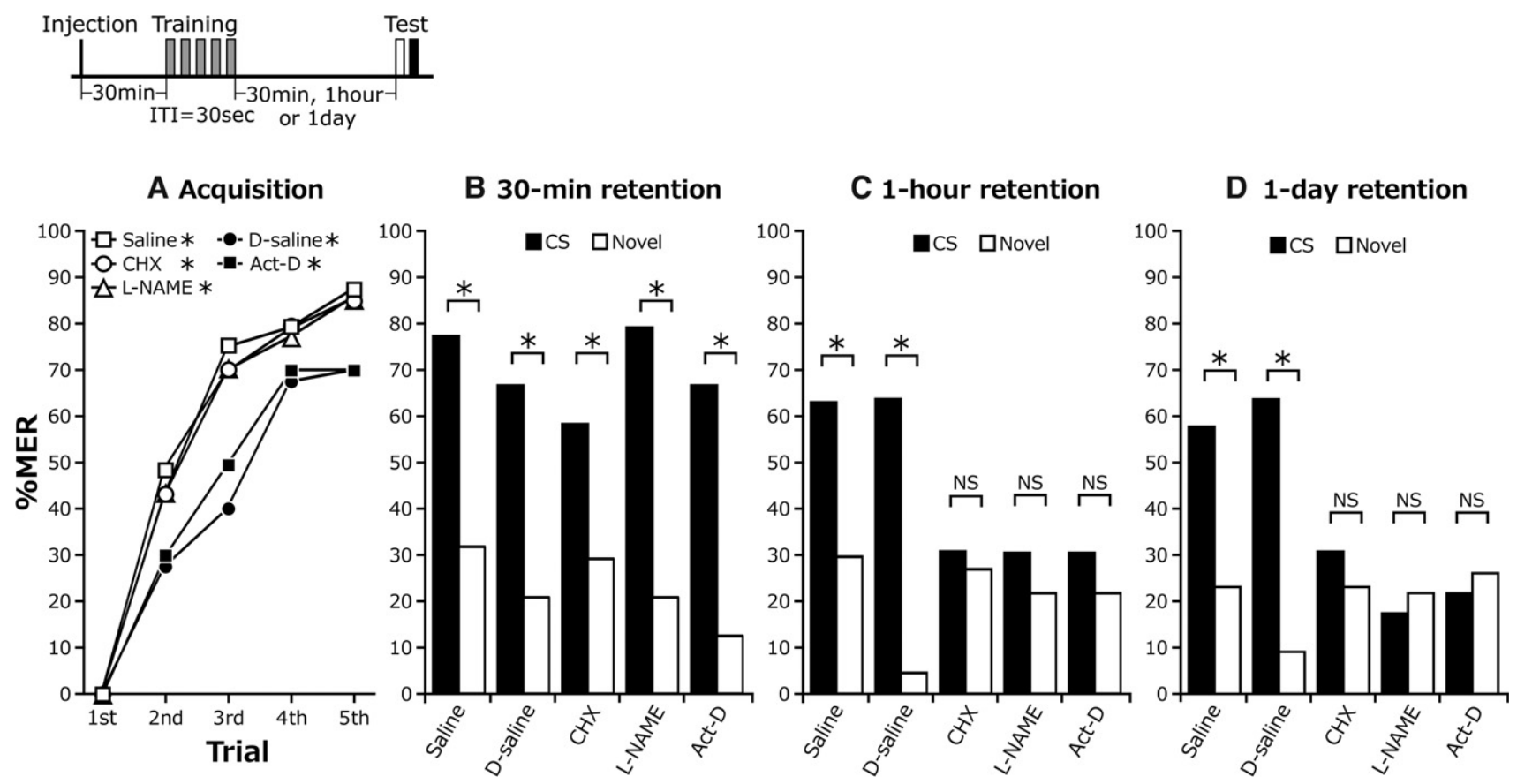

Figure 3. Pharmacological dissection of transcription- and translation-dependent LTM with earlier memory phase. $(A)$ Acquisition performances in groups injected with saline and saline containing DMSO (D-saline group), CHX, L-NAME, or Act-D. The time schedule of the experiment is shown above the figure. Percentage of MERs to the CS significantly increased with the progress of training in all groups (Cochran's Q test: saline, $n=75$, $P=2.2 \times 10^{-16}, \chi^{2}=156.82 ; \mathrm{D}$-saline, $n=68, P=2.2 \times 10^{-16}, \chi^{2}=115.01 ; \mathrm{CHX}, n=76, P=2.2 \times 10^{-16}, \chi^{2}=159.42 ; \mathrm{L}-\mathrm{NAME}, n=66, P=$ $2.2 \times 10^{-16}, x^{2}=142.6$; Act-D, $\left.n=80, P=2.2 \times 10^{-16}, \chi^{2}=118.14\right)$. Percentages of MERs to the CS at the fifth trial did not significantly differ among groups (LR test: saline, CHX vs. L-NAME: $P=0.405$, deviance $=1.8, \mathrm{df}=2$; Fisher's exact test: Act-D vs. $\mathrm{D}$-saline: $P=0.71$, odds ratio $=$ 1.18; D-saline vs. saline: $P=0.052$, odds ratio $=2.5)$. $(B-D)$ Each group received a retention test at $30 \mathrm{~min}, 1 \mathrm{~h}$, or $1 \mathrm{~d}$ after training. Percentage of MERs to the CS (black bar) was statistically compared with that to a novel odor (white bar) in each group (McNemar's test: 30 min: saline, $n=22$, $P=0.0094, x^{2}=6.75 ; D$-saline, $n=24, P=0.0026, x^{2}=9.09 ; \mathrm{CHX}, n=24, P=0.046, \chi^{2}=4.0 ;$ L-NAME, $n=24, P=0.0011, \chi^{2}=10.56 ;$ Act-D, $n=24, P=0.00087, \chi^{2}=11.08 ; 1$ h: saline, $n=27, P=0.027, \chi^{2}=4.92 ; D$-saline, $n=22, P=0.00087, \chi^{2}=11.08 ; C H X, n=26, P=1, \chi^{2}=0 ;$ L-NAME, $n=19, P=0.68, \chi^{2}=0.17$; Act-D, $n=23, P=0.68, \chi^{2}=0.17 ; 1$ d: saline, $n=26, P=0.0077, \chi^{2}=7.11 ; \mathrm{D}$-saline, $n=22, P=0.0033$, $\chi^{2}=8.64 ; \mathrm{CHX}, n=26, P=0.68, \chi^{2}=0.17$; L-NAME, $n=23, P=1, \chi^{2}=0$; Act-D, $\left.n=23, P=1, \chi^{2}=0\right) .\left({ }^{*}\right) P<0.05$, NS: $P>0.05$.

\section{Dissection of anesthesia-sensitive short-term memory from later memory phases}

To discriminate anesthesia-sensitive STM from later memory phases, we performed $\mathrm{CO}_{2}$ anesthesia at various times after twotrial conditioning with a 30 -sec ITI. Five groups received 10 -sec $\mathrm{CO}_{2}$ treatment at $30 \mathrm{sec}, 5 \mathrm{~min}, 7 \mathrm{~min}, 15 \mathrm{~min}$, or $1 \mathrm{~h}$ after completion of training. A control (intact) group received the same training but no anesthetic treatment. The percentages of MERs increased significantly with progress of training in all groups (Fig. 4A). The percentages of MERs at the second trial did not significantly differ among groups. In the 1 -d retention test, the intact group and the groups subjected to anesthesia at $7 \mathrm{~min}$ after training or later exhibited significantly higher percentages of MERs to the CS than to a novel odor. In contrast, the groups that received anesthetic treatment $30 \mathrm{sec}$ or $5 \mathrm{~min}$ after training exhibited no significantly higher percentages of MERs to the CS than to a novel odor (Fig. 4B). Thus, we characterize the memory up to $5 \mathrm{~min}$ after training as anesthesia-sensitive STM and the memory at $7 \mathrm{~min}$ after training or later as anesthesia-insensitive MTM.

\section{Biphasic memory retention curve after one-trial conditioning}

It has been reported that multiple trials, but not a single trial, produce long-lasting memory in many learning systems of animals (Tully et al. 1994; Gerber et al. 1998; Cepeda et al. 2006; Philips et al. 2007). We next studied the effect of one-trial conditioning. Groups of cockroaches received one-trial conditioning and then received a retention test at various times after conditioning (Fig. 5A). Percentages of MERs to the CS in the retention test were significantly higher than that before conditioning (i.e., in the conditioning trial) in the 20-sec, 30-sec, 2-min, 5-min, 15-min, 30-min, and 1-d retention test groups, indicating successful memory retention, but those in the 7-min, 10-min, and 1-h groups were not significantly higher than that before conditioning. A comparison among groups showed that percentages of MERs in the 20-sec, 30-sec, 2-min, and 30-min groups, but not the 5-min, 7-min, 15-min, 1-h, and 1-d groups, were significantly higher than that in the 10-min group. Thus, the retention curve after a single training trial is biphasic, showing an initial decay with a trough at 10 min after training and then an increase with a peak at 30 min after training and then a decay.

We next investigated whether the memory after a single pairing trial is CS-specific. Two groups were subjected to one-trial conditioning, and one group was presented with the paired odor (CS) and the other group was presented with a novel odor at $30 \mathrm{sec}$ after training. There was no significant difference between percentages of MERs in the two groups (Fig. 5B), indicating that 30-sec memory after a single trial is not CS-specific, reflecting a nonassociative effect (sensitization). Another three groups were subjected to one-trial conditioning and were presented with the $\mathrm{CS}$ and a novel odor at $30 \mathrm{~min}, 1 \mathrm{~h}$, and $1 \mathrm{~d}$ after training. The 30-min retention group exhibited a significantly higher percentage of MERs to the CS than to a novel odor (Fig. 5C), indicating 

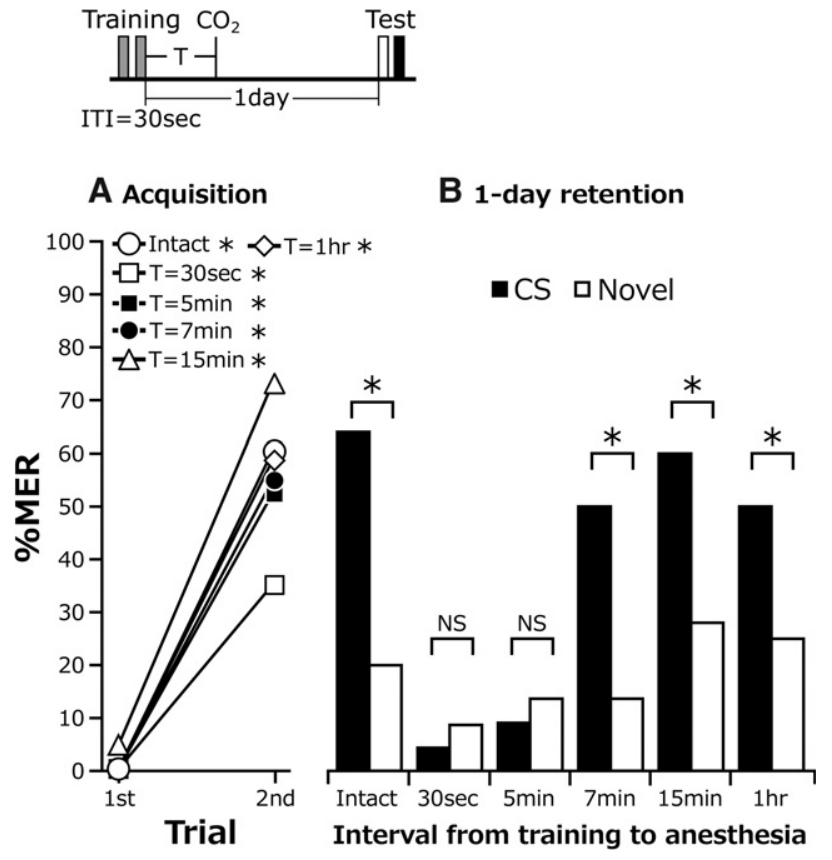

Figure 4. Dissection of anesthesia-sensitive and anesthesia-resistant memories. Cockroaches in five groups received two-trial conditioning with a 30 -sec ITI and then received $\mathrm{CO}_{2}$ anesthesia at $30 \mathrm{sec}, 5 \mathrm{~min}, 7$ $\mathrm{min}, 15 \mathrm{~min}$, or $1 \mathrm{~h}$ after the last trial. Another group received the same training but no $\mathrm{CO}_{2}$ anesthesia. The time schedule of the experiment is shown above the figure. (A) Acquisition performance. Percentages of MERs to the CS significantly increased with training (Cochran's Q test: intact: $n=25, P=0.00011, \chi^{2}=15 ; 30$ sec: $n=23, P=0.0046, \chi^{2}=$ $8 ; 5$ min: $n=22, P=0.0001, \chi^{2}=15 ; 7 \min : n=22, P=0.00053$, $\chi^{2}=12 ; 15 \min : n=25, P=0.00031, \chi^{2}=13 ; 1 \mathrm{~h}: n=22, P=0.043$, $\left.\chi^{2}=10\right)$. Percentages of MERs to the CS at the second trial did not significantly differ among the groups (LR test: $P=0.2$, deviance $=7.23, \mathrm{df}=5$ ) $(B)$ One-day retention after two-trial conditioning. Percentage of MERs to the CS was statistically compared with that to a novel odor in each group (McNemar's test: intact: $n=24, P=0.00018, \chi^{2}=15 ; 30$ sec: $n=23$, $P=1, \chi^{2}=0 ; 5$ min: $n=22, P=1, \chi^{2}=0 ; 7$ min: $n=22, P=0.027$, $\chi^{2}=4.90 ; 15 \mathrm{~min}, n=25, P=0.043, \chi^{2}=4.08 ; 1 \mathrm{~h}: n=22, P=$ $\left.0.027, \chi^{2}=4.90\right)$. ( $\left.{ }^{*}\right) P<0.05$, NS: $P>0.05$.

that the 30-min memory after a single trial is CS-specific. In contrast, no CS-specific memory was found in the 1-h and 1-d retention tests. We thus conclude that one-trial conditioning induces STM that is not CS-specific and 30-min memory that is CS-specific. One-trial conditioning induced a very low level of 1-d memory, which was not CS-specific.

\section{Effects of two- or three-trial conditioning with different} ITIs on LTM formation

We next investigated retention after two- or three-trial conditioning with various ITIs to compare with that after single-trial (Fig. 5) or five-trial (Fig. 2C,D) conditioning. At first, six groups of cockroaches were subjected to two-trial conditioning with $30-\mathrm{sec}$, 5-min, 7-min, 10-min, 15-min, or 1-h ITIs. The 30-sec, 5-min, 7-min, and 10-min ITI groups exhibited significant increases in percentages of MERs with training (Fig. 6A), but the 15-min and 1-h ITI groups did not. A comparison among groups showed that the percentages of MERs at the second trial in the 30-min, 5-min, 7-min, and 10-min groups, but not in the 15-min group, were significantly higher than that in the 1-h group. A slight difference in the performances of the 15-min group shown in Figures 5A, 6A may reflect incidental data variation due to the small sample size.
In the 1 -d retention test, the 30 -sec and 5-min ITI groups exhibited significantly greater percentages of MERs to the CS than to a novel odor (Fig. 6B). On the other hand, the 7-min, 10-min, 15-min, 30-min, and 1-h ITI groups did not exhibit significantly greater percentages of MERs to the CS than to a novel odor, indicating no CS-specific memory. Thus, we conclude that two-trial conditioning with ITIs of $5 \mathrm{~min}$ or shorter induces CS-specific LTM but that two-trial conditioning with longer ITIs does not. These observations again do not match results of studies in many animals showing that training with longer ITIs is more effective than training with shorter ITIs for inducing LTM (Tully et al. 1994).

Next, we studied the effects of three-trial conditioning with 5-min, 7-min 10-min, and 15-min ITIs. All of the groups exhibited significant increases in percentages of MERs with training (Fig. 6C). Percentages of MERs at the third trial did not significantly differ among groups. In the 1-d retention test, all of the groups exhibited significantly higher percentages of MERs to the CS than to a novel odor (Fig. 6D). Thus, three-trial conditioning with a wide range of ITIs induces CS-specific LTM.

Retention after 1-trial training

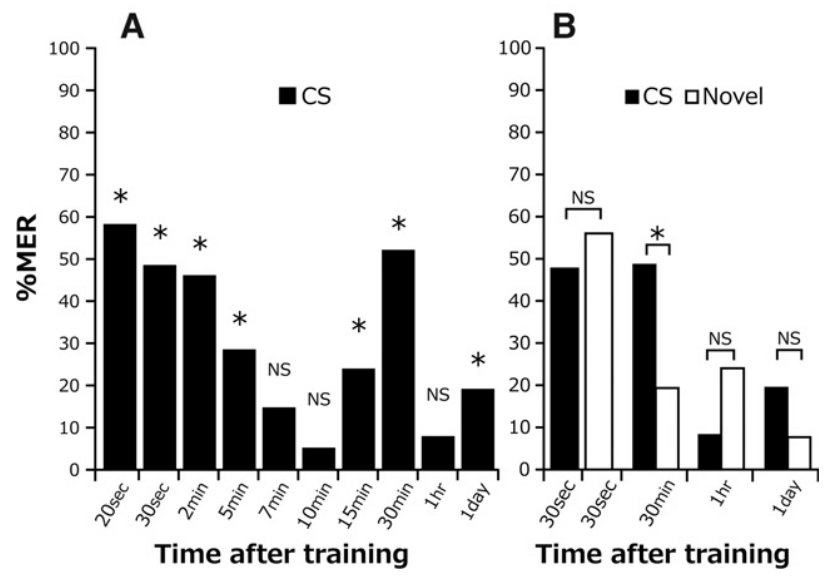

Figure 5. Memory retention after one-trial conditioning. (A) Cockroaches in 10 groups were subjected to one-trial conditioning and then subjected to a retention test at different times after the trial. Percentage of MERs in each retention test was compared with that at the first trial (i.e., prior to the first CS-US pairing) (Cochran's $Q$ test: 20 sec, $n=24, P=0.00018, \chi^{2}=14.0 ; 30 \mathrm{sec}, n=35, P=3.73 \times 10^{-5}$, $\chi^{2}=17.0 ; 2 \min , n=26, P=0.00058, \chi^{2}=12.0 ; 5 \min , n=49, P=$ $0.00018, \chi^{2}=14.0 ; 7 \min , n=54, P=0.058, \chi^{2}=3.6 ; 10 \mathrm{~min}, n=$ $38, P=0.16, \chi^{2}=2.0 ; 15 \mathrm{~min}, n=25, P=0.014, \chi^{2}=6.0 ; 30 \mathrm{~min}$, $n=31, P=0.00017, \chi^{2}=15.0 ; 1 \mathrm{~h}, n=25, P=0.16, \chi^{2}=2.0 ; 1 \mathrm{~d}$, $\left.n=26, P=0.025, \chi^{2}=5.0\right)$. The percentage of MERs in the 10-min group was compared with those in other groups (LR test: $P=6.43 \times$ $10^{-7}$, deviance $=51.19, \mathrm{df}=9$; Fisher's exact test: $20 \mathrm{sec}$ vs. $10 \mathrm{~min}$ : $P=5.23 \times 10^{-6}$, odds ratio $=23.54,30 \mathrm{sec}$ vs. $10 \mathrm{~min}: P=2.87 \times$ $10^{-5}$, odds ratio $=16.32 ; 2$-min vs. $10 \mathrm{~min}: P=0.00015$, odds ratio $=$ $14.69 ; 5$ min vs. $10 \mathrm{~min}: P=0.017$, odds ratio $=6.23 ; 7-\mathrm{min}$ vs. 10 min: $P=0.18$, odds ratio $=3.09 ; 15 \mathrm{~min}$ vs. $10 \mathrm{~min}: P=0.049$, odds ratio $=5.52 ; 30 \mathrm{~min}$ vs. $10 \mathrm{~min}: P=5.71 \times 10^{-5}$, odds ratio $=15.23 ; 1$ h vs. $10 \mathrm{~min}: P=1$, odds ratio $=1.55 ; 1 \mathrm{~d}$ vs. $10 \mathrm{~min}: P=0.11$, odds ratio $=4.18)$. $(B)$ Retention performance. First two bars: Cockroaches in two groups were subjected to one-trial conditioning and then presented with the CS or a novel odor at $30 \mathrm{sec}$ after the training trial. Percentage of MERs to the CS did not significantly differ from that to a novel odor (novel) (Fisher's exact test: $P=0.61$, odds ratio $=1.34$; CS, $n=35$, novel odor, $n=25$ ). Next six bars: Cockroaches in three groups were subjected to one-trial conditioning and then a retention test at $30 \mathrm{~min}, 1 \mathrm{~h}$ or $1 \mathrm{~d}$ after conditioning. Percentage of MERs to the CS was statistically compared with that to a novel odor in each group (McNemar's test: 30 $\min , n=31, P=0.034, \chi^{2}=4.27 ; 1 \mathrm{~h}, n=25, P=0.13, \chi^{2}=2.25 ; 1$ d, $\left.n=26, P=0.45, \chi^{2}=0.57\right) .\left(^{*}\right) P<0.05$, NS: $P>0.05$. 
Effects of different numbers of trials with 5-min ITIs on LTM formation

Our observations that two- or three-trial conditioning but not five-trial conditioning with 5-min ITIs produces LTM (Figs. 2D, 6B,D) are paradoxical because increasing the number of conditioning trials usually strengthens LTM (Tully et al. 1994). To better clarify the effect of increasing the number of trials with 5-min ITIs on LTM formation, four groups of cockroaches were subjected to four, six, seven, and 10 trials with 5-min ITIs, and 1-d retention was tested. The results are shown in Figure 7 together with results for the two-, three-, and five-trial groups.

In the 1-d retention test, the group that received four trials did not exhibit a significant level of CS-specific memory as in the case of the five-trial group. On the other hand, the six-, seven-, and 10-trial groups exhibited significantly higher percentages of MERs to the CS than to a novel odor (Fig. 7). Thus, the effect of increasing the number of trials with 5-min ITIs on LTM formation is complicated: LTM is formed by two or three trials but not by four or five trials and is again formed by six, seven, and 10 trials. It appears that the fourth trial inhibits the ongoing process of LTM formation, since LTM should have been formed without the fourth trial. It also appears that with further addition of two trials, the inhibitory effect is overwhelmed by the facilitatory effect for LTM formation.

\section{Effects of three-trial conditioning with different intervals between the second and third trials on LTM formation}

Based on the results shown in Figure 7, we proposed a model in which (1) each conditioning trial has both a facilitatory effect and an inhibitory effect on LTM formation, (2) the strength of the effects varies depending on time intervals from preceding trials, and (3) summation of the effects of all trials determines whether LTM is formed. To clarify time intervals from preceding trials with which a trial inhibits LTM formation, we designed a three-trial conditioning experiment in which the interval between the first and second trials $\left(\mathrm{I}_{1-2}\right)$ was fixed at $30 \mathrm{sec}$ and that between the second and third trials $\left(\mathrm{I}_{2-3}\right)$ varied from 5 to $30 \mathrm{~min}$ and thus $\mathrm{I}_{1-3}$ varied from 5.5 to $30.5 \mathrm{~min}$. Retention was tested $1 \mathrm{~d}$ after conditioning. If the three-trial conditioning does not form LTM, the third trial should have cancelled out the ongoing process of LTM formation since the first two trials, if not followed by the third trial, should have led to LTM formation (Fig. 6).

All of the groups exhibited significant increases in percentages of MERs with training trials (Fig. 8A). In the 1-d retention test, the percentage of MERs to the CS was significantly higher than that to a novel odor in the 5-, 20-, and $30-\mathrm{min}_{2-3}$ groups (Fig. $8 \mathrm{~B})$, whereas the percentage of MERs to the CS did not significantly differ from that to a novel odor in the 10- and 15-min $\mathrm{I}_{2-3}$ groups (10-min $\mathrm{I}_{2-3}, n=23, P=1, \chi^{2}=0 ; 15-$ min $_{2-3}, n=$ $\left.24, P=1, \chi^{2}=0\right)$. The results suggest that the third trial inhibits the ongoing process of LTM formation when it is preceded by the first and second trials with a range of intervals of 10-15.5 $\min \left(\mathrm{I}_{2-3}=10\right.$ or $15 \mathrm{~min}$ and $\mathrm{I}_{1-3}=10.5$ or $\left.15.5 \mathrm{~min}\right)$ but not when it is preceded by trials with shorter or longer intervals.

\section{Inhibitory effect of the trial is pairing-specific}

We finally investigated whether the inhibitory effect is pairingspecific. Two groups received two-trial conditioning with 30-sec $\mathrm{I}_{1-2}$, and a CS or US was presented alone 10 min later. Both groups exhibited normal acquisition performance until the second trial (Fig. 8C): The US-only group exhibited no MER at the third trial because no odor was presented. In the 1-d retention test, both groups exhibited significantly higher percentages of MERs to the CS than to a novel odor (Fig. 8D), indicating that presentation of a CS or a US alone has no inhibitory effect on the formation of LTM. Thus, the effect of a trial to inhibit LTM formation is pairing-specific.

\section{Discussion}

We used olfactory conditioning of MER to investigate conditioning parameters for formation of protein synthesis-dependent LTM in cockroaches. Conditioning of MER is advantageous for analysis of the effects of conditioning parameters for LTM formation compared with our previous conditioning procedures (operant conditioning procedure: Sakura and Mizunami 2001; Sakura et al. 2002; classical conditioning and operant testing procedure: Watanabe 


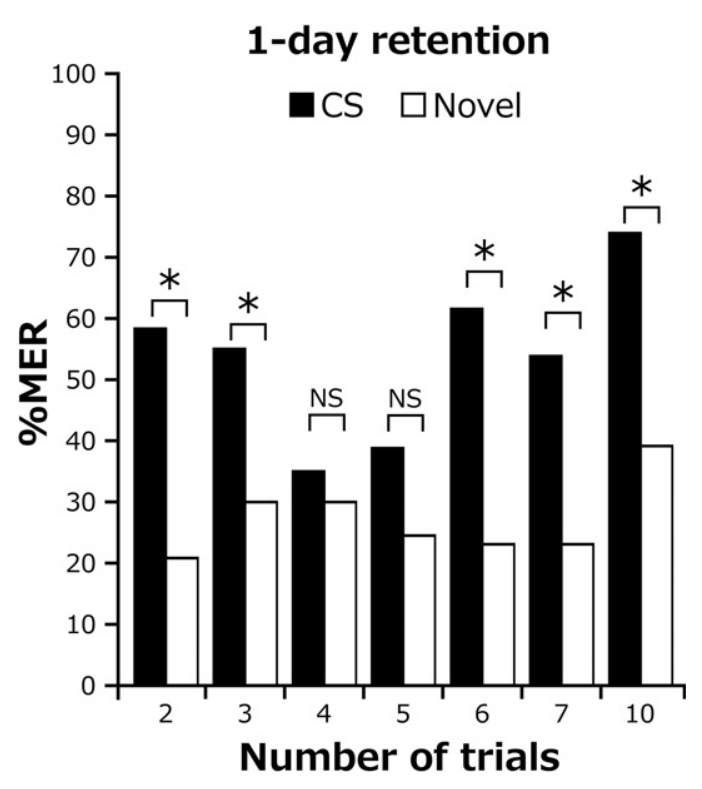

Figure 7. One-day retention after conditioning with different numbers of trials and with 5-min ITls. The percentage of MERs to the CS was statistically compared with that to a novel odor in two-, three-, four-, five-, six-, seven-, or 10-trial conditioning groups with 5-min ITIs (McNemar's test: four-trial, $n=20 P=1, \chi^{2}=0$; six-trial, $n=26, P=0.024, \chi^{2}=5.06$; 7-trial, $n=26, P=0.013, \chi^{2}=6.13 ; 10$-trial, $n=24, P=0.043, x^{2}=$ 4.08; for two, three, and five trials, see legends of Figs. 2,6$) .\left(^{*}\right) P<$ 0.05 , NS: $P>0.05$.

et al. 2003; and conditioning of activities of salivary neurons: Watanabe and Mizunami 2006, 2007; Watanabe et al. $2008,2011)$ in that retention can be evaluated very easily.

We observed that the process for the formation of protein synthesis-dependent LTM has some unique features in cockroaches in that (1) multiple trials with short intervals (20-30 sec), called massed training, are more effective than trials with long ( $>5 \mathrm{~min}$ ) intervals, called spaced training, for formation of protein synthesis-dependent LTM and (2) a conditioning trial inhibits or facilitates LTM formation depending on the time interval from the preceding trial. To our knowledge, the former has been reported very rarely in other animals and the latter has never been reported in other animals. These features will be discussed in more detail below.

\section{Memory phases after a single trial and multiple trials}

We observed that memory after two-trial conditioning with a 30-sec interval can be separated into three phases, anesthesia-sensitive STM, anesthesia-insensitive MTM, and protein synthesis-dependent LTM (Figs. 3, 4). The STM lasts up to $\sim 5$ min after training, the MTM develops $\sim 7$ min after conditioning and lasts up to $\sim 30 \mathrm{~min}$ after training, and the LTM is fully developed $1 \mathrm{~h}$ after training.

Memory after a single conditioning trial was biphasic, exhibiting an initial decay with a trough at $10 \mathrm{~min}$ after training and a peak at $30 \mathrm{~min}$ after training. The time course of the second memory phase matches the late phase of the anesthesia-insensitive MTM. We thus propose that MTM can be divided into early MTM (eMTM) with a peak at $10 \mathrm{~min}$ and late MTM (IMTM) with a peak at $30 \mathrm{~min}$ : following this scheme, memory after a single trial consists of STM and IMTM, and memory after two trials with a 30-sec ITI consists of four memory phases, namely, STM, eMTM, IMTM and LTM, as shown in Supplemental Figure S1. It should be cautioned, however, that separation of MTM into eMTM and IMTM remains hypothetical until evidence that they are based on different biochemical or cellular processes is obtained.

We observed that protein synthesis-dependent LTM is fully developed $1 \mathrm{~h}$ after conditioning in cockroaches (Fig. 3), and this formation of LTM is the fastest so far reported in insects (8 $\mathrm{h}$ in crickets, Matsumoto et al. 2003; $1 \mathrm{~d}$ in fruit flies, Tully et al. 1994; 3 d in honeybees, Menzel 1999; Giurfa and Sandoz 2012). This rapidly formed LTM can be maintained for at least $5 \mathrm{~d}$ : we observed that memory formed by five trials with 30 -sec ITIs lasted at least for $5 \mathrm{~d}$ (data not shown). It is tempting to speculate that such rapid formation of LTM is related to the lifestyle and behaviors of cockroaches, but whether this feature can be generalized to conditioning with CS and US other than the odor CS and sucrose US needs to be investigated to enable solid discussion on this subject.

Memory after a single conditioning trial shows the lowest level at $10 \mathrm{~min}$ after training. A lapse of memory after weak training has been referred to as the Kamin effect (Kamin 1957) and has been reported in many vertebrates and invertebrates (Klein and Spear 1970; Riege and Cherkin 1971; Sanders and Barlow 1971;

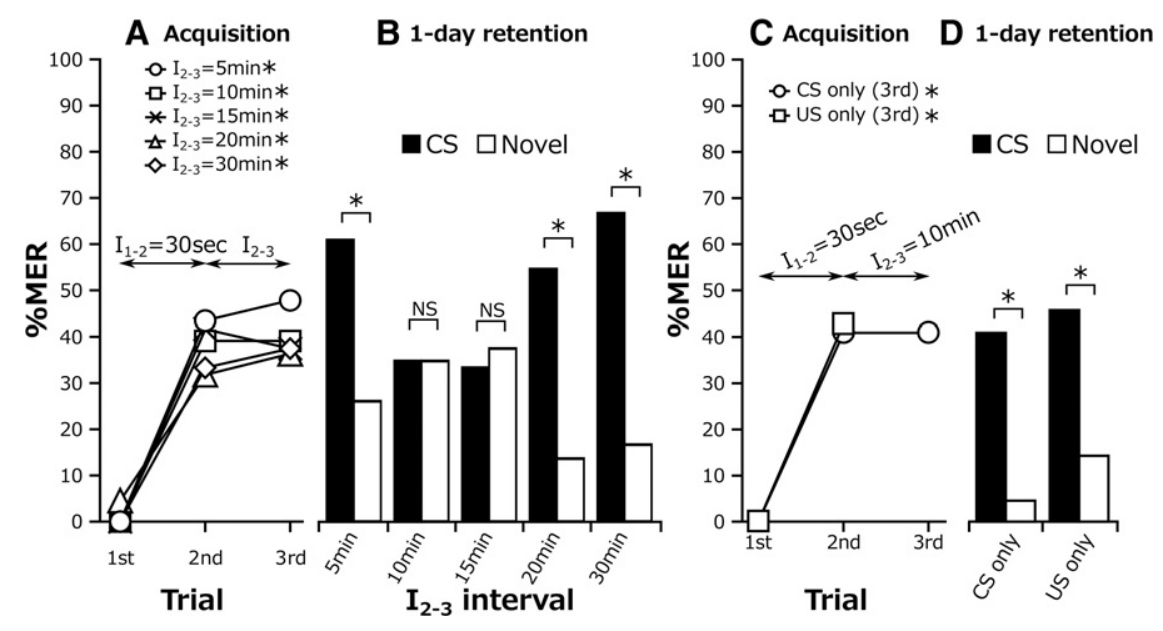

Figure 8. Acquisition and 1-d retention after three-trial conditioning with 30-sec $\mathrm{I}_{1-2}$ and different $\mathrm{I}_{2-3}(A, B)$ and after two pairing trials with a 30 -sec interval $\left(\mathrm{I}_{1-2}\right)$ and subsequent presentation of $C S$ or US alone with a 10-min interval $\left(I_{2-3}\right)(C, D)$. (A) Acquisition performance. The change in percentages of MERs to the CS with progress of training was statistically evaluated (Cochran's Q test: 5 -min I $\mathrm{I}_{2-3}, n=$ $23, P=0.00019, \chi^{2}=17.08 ; 10-\operatorname{min~I}_{2-3}, n=23, P=0.0045, \chi^{2}=10.8 ; 15-\mathrm{min} \mathrm{I}_{2-3}, n=24, P=$ $0.0047, x^{2}=10.71 ; 20-\mathrm{min} \mathrm{I}_{2-3}, n=22, P=0.0084, x^{2}=9.56 ; 30-\mathrm{min} \mathrm{I}_{2-3}, n=24, P=0.0023$, $\left.\chi^{2}=12.17\right)$. (B) One-day retention performance. The percentage of MERs to the CS was statistically compared with that to a novel odor in each group (McNemar's test: 5 -min $I_{2-3}, n=23, P=0.027$, $\chi^{2}=4.9 ; 10-\operatorname{min~I}_{2-3}, n=23, P=1, \chi^{2}=0 ; 15-\operatorname{min~I}_{2-3}, n=24, P=1, \chi^{2}=0 ; 20-\mathrm{min} \mathrm{I}_{2-3}, n=$ $22, P=0.0077, \chi^{2}=7.11 ; 30-\mathrm{min} \mathrm{I}_{2-3}, n=24, P=0.0015, \chi^{2}=10.08$ ). (C) Acquisition performance after two pairing trials with a 30-sec interval $\left(I_{1-2}\right)$ and subsequent presentation of CS or US alone with a 10-min interval $\left(\mathrm{I}_{2-3}\right)$. The percentage of MERs in the first trial was statistically compared with that in the second trial in each group (Cochran's $Q$ test: CS only, $n=22, P=0.002, \chi^{2}=12.46$; US only, $n=35$, $\left.P=3.06 \times 10^{-7}, x^{2}=30.0\right)$. (D) One-day retention performance. The percentage of MERs to the CS was statistically compared with that to a novel odor in each group (McNemar's test: CS only, $n=22$, $P=0.027, x^{2}=4.9 ;$ US only, $\left.n=35, P=0.0055, x^{2}=7.69\right)$. $\left(^{*}\right) P<0.05$, NS: $P>0.05$. 
Rosenzweig et al. 1993; Hellstern et al. 1998) including honeybees (Menzel 1979; 1999; Gerber et al. 1998; Gerber and Menzel 2000). In the mollusk Lymnaea (Marra et al. 2013), it has been concluded that the dip in memory corresponds to transitions between different phases of memory that have different molecular requirements. Notably, in the cockroach, a 10-min interval corresponds not only to the interval in which formation of LTM is difficult but also to that in which a training trial suppresses the ongoing process of LTM formation. Indeed, the results of experiments shown in Figure 8A,B strongly suggest that a trial that was preceded by trials with a range of intervals of 10-15.5 min cancels out the ongoing processes of LTM formation. To our knowledge, no similar cancelation of the ongoing process of LTM formation by a conditioning trial has been reported in any animals, except for the "overtraining effect" (Brookshire et al. 1961; Ishida and Papini 1997), in which excessive training in a condition of low motivation (e.g., exhaustion) leads to inhibition of LTM formation. It is obvious that the trial number- and ITI-specific inhibition of LTM formation observed in this study differs from the overtraining effect.

\section{Effects of training parameters on LTM formation}

We observed no evidence of a "trial-spacing effect" for LTM induction at least for ITIs of 20 sec or longer in cockroach olfactory learning. This is in contrast to the fact that a spacing effect has been ubiquitously observed in many animals; that is, multipletrial training with sufficient intervals (spaced training) leads to formation of protein synthesis-dependent LTM, but training with short intervals (massed training) is less effective. In insects, the spacing effect has been reported in fruit flies (Tully et al. 1994), honeybees (Gerber et al. 1998; Menzel et al. 2001) and crickets (Matsumoto and Mizunami 2002). It should be cautioned, however, that a spacing effect might appear if we could perform training with ITIs of $<20 \mathrm{sec}$. Moreover, because many previous studies on the spacing effect have been performed using weak conditioning protocols, in which many trials are needed to establish LTM, it needs to be investigated whether the spacing effect can be found by training with a weak US.

Molecular mechanisms underlying the spacing effect have been studied in fruit flies (Pagani et al. 2009), and it has been proposed that activation of the consolidation process for LTM formation requires multiple waves of activation of MAPK (mitogenactivated protein kinase): spaced training (with a 900-sec ITI) produces multiple waves of MAPK activation, but massed training (with a 45-sec ITI) does not, due to the slow kinetics of MAPK activation. In rats and the sea slug Aplysia, it has been shown that persistent activation of MAPK activates cAMP response elementbinding protein (CREB), which serves as a switch to form LTM in many animals including the fruit fly (Margulies et al. 2005; Philips et al. 2007; Naqib et al. 2012; Zhang et al. 2012). Based on these findings, we propose that the absence of a spacing effect in cockroaches can be accounted for by a model in which (1) kinetics of the biochemical process activated by each trial is rapid and thus multiple trials with 20 -sec intervals can produce multiple waves of biochemical processes and (2) the summation effect of multiple waves to trigger the biochemical process leading to LTM formation is more effective when the ITI is short (5 min or less). In the following section, we elaborate on this model so that other observations in this study can be accounted for.

It was an unexpected observation that a conditioning trial inhibits LTM formation when the intervals from preceding trials are 10-15.5 min (Fig. 8A). To account for this observation, we propose a model in which we assume that (1) each trial transiently activates a biochemical process (process A) and (2) multiple activation of process $\mathrm{A}$ triggers sustained activation of process $\mathrm{F}$ (facilitatory process), which leads to formation (or consolidation) of LTM, as is assumed in the model proposed by Pagani et al. (2009) for fruit flies. We also assume that (3) a training trial induces process I, which inhibits process $\mathrm{F}$, when the interval from the preceding trial is in a range of $10-16$ min or when the number of preceding trials with intervals in this range is larger than the number of trials with intervals outside this range (i.e., $<10 \mathrm{~min}$ or $>16 \mathrm{~min})$. The model has been mathematically described in Supplemental Data 1.

In Figure 9A,B, we show that the model accounts for observations in this study in that (1) a conditioning trial can inhibit the ongoing process of LTM formation shown in Figure 8 (Fig. 9A), and (2) three trials, but not two trials, with a 10 -min or 15-min ITI lead to LTM formation shown in Figure 6 (Fig. 9B). In Figure $9 \mathrm{C}, \mathrm{D}$, we show that the model accounts for the observations that two, three, six, or more trials with 5-min ITIs lead to LTM formation but that four or five trials do not (Fig. 7) if we assume that process I lasts for at least $5 \mathrm{~min}$ (but no more than $10 \mathrm{~min}$ ) once it is activated. Therefore, simple modifications of a model proposed for flies accounts for unique features of the memory system of cockroaches. Although more studies need to be performed to evaluate the validity of this model, the model should provide a starting point for further quantitative analysis of the interaction of inhibitory and facilitatory processes to form LTM observed in cockroaches.

\section{Conclusion}

We conclude that each training trial has a facilitatory or inhibitory effect on LTM formation depending on the intervals from preceding trials in olfactory conditioning in cockroaches. Cellular and molecular mechanisms underlying the interaction of these facilitatory and inhibitory effects are fascinating future subjects, and the model we proposed should provide a starting point for such study. We previously showed that activation of nitric oxide synthase (NOS) participates in LTM formation in cockroaches (Matsumoto et al. 2013), and thus activation of NOS should comprise one of biochemical processes to activate the facilitatory process (process F) in the model. Cockroaches should provide a unique opportunity to study the interaction of facilitatory and inhibitory processes for LTM formation and its underlying cellular and biochemical mechanisms.

An important future subject is to investigate whether unique characteristics of memory formation in appetitive olfactory learning can be generalized to other forms of learning in cockroaches. Such studies should help to clarify general characteristics of the memory system of cockroaches and hence allow discussion of how unique properties of the memory system are related to life styles and evolutionary history of animals.

\section{Materials and Methods}

\section{Animals}

Adult male cockroaches, Periplaneta americana, maintained in a colony under a light-dark cycle of $14 \mathrm{~h}: 10 \mathrm{~h}$ at $28^{\circ} \mathrm{C}-30^{\circ} \mathrm{C}$ were used. One week prior to conditioning, 30-40 cockroaches were collected from the colony into a plastic container. The container was placed in a rearing room with a reversed light-dark cycle of $12 \mathrm{~h}: 12 \mathrm{~h}$ (light period: $20: 00-8: 00$ ) at $25^{\circ} \mathrm{C}-27^{\circ} \mathrm{C}$. Drinking water was provided ad libitum. No food was provided to enhance motivation to uptake sucrose solution. One day before the training, cockroaches were anesthetized by $\mathrm{CO}_{2}$ and individually isolated into 200-mL beakers. The wall of each beaker was smeared with liquid paraffin to prevent the cockroaches from escaping, and the floor of the beaker was covered with black 


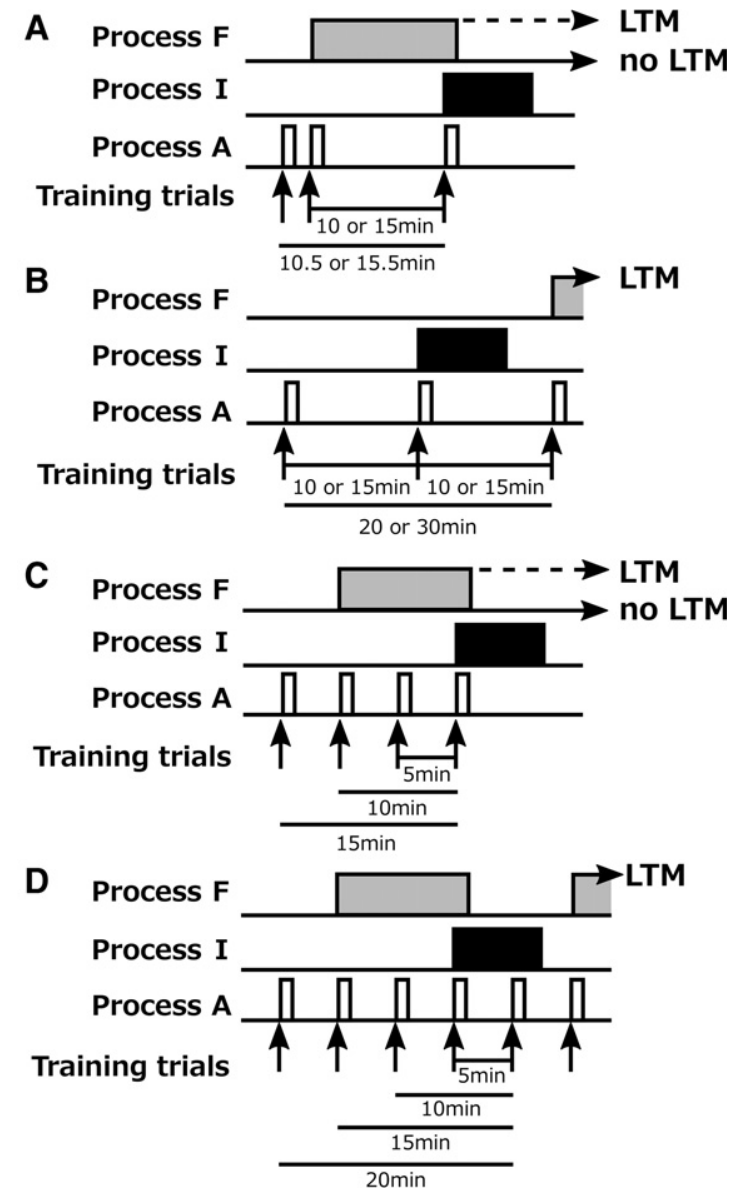

Figure 9. A hypothetical model to account for the effects of number of trials and ITI on LTM formation. The model assumes that (1) each training trial produces transient activation of biochemical process A, (2) multiple activations of process A trigger sustained activation of biochemical process $F$, (3) sustained activation of process $F$ produces protein synthesisdependent LTM, (4) the effect of activation of process $A$ to trigger $F$ is weaker when the intervals from preceding activations are $>5 \mathrm{~min}$, and thus two trials are sufficient to trigger process $\mathrm{F}$ when the ITI is $5 \mathrm{~min}$ or less, but three trials are required when the ITI is $>5 \mathrm{~min}$, (5) when a trial is preceded by a trial with an interval in the range of 10-16 min, the trial triggers process $\mathrm{I}$, which inhibits process $\mathrm{F}$, and (6) when a trial is preceded by multiple trials, process I is triggered when the number of preceding trials with intervals in the range of $10-16 \mathrm{~min}$ is larger than the number of trials with intervals outside this range $(<10 \mathrm{~min}$ or $>16$ $\min )$. In $A$, we show how the model accounts for the observation that three-trial conditioning with $\mathrm{I}_{1-2}=30 \mathrm{sec}, \mathrm{I}_{2-3}=10$ or $15 \mathrm{~min}$ and $\mathrm{I}_{1-3}=10.5$ or $15.5 \mathrm{~min}$ does not lead to LTM formation (Fig. 8). The second trial triggers process $F$, but it does not trigger process $I$. The third trial triggers process $I$ since $I_{1-3}=10.5 \mathrm{~min}$ and $\mathrm{I}_{2-3}=10 \mathrm{~min}$. Process I suppresses process $\mathrm{F}$ and thus no LTM formation occurs. In $B$, we show how the model accounts for the observation that three-trial training with 10-min or 15-min ITIs induced LTM formation but that twotrial training did not (Fig. 6). The second trial triggers process I but not process $F$, whereas the third trial triggers process $F$ and hence LTM formation occurs. In $C$ and $D$, we show how the model accounts for the observation that two-, three-, or six-trial training with a 5-min ITI produced LTM but that four- or five-trial training did not (Fig. 7). We observed that fivetrial training with 5-min ITIs did not produce LTM, but our model assumes that the fifth trial does not activate process I, since it is preceded by the first to fourth trials for $20,15,10$, and $5 \mathrm{~min}$ and thus the number of trials with intervals in the range of $10-16 \mathrm{~min}$ is equal to the number of trials with intervals outside this range $(D)$. We thus added an assumption that activation of process I is maintained for at least 5 min (but not more than $10 \mathrm{~min}$ ) once it is activated. For mathematical description of the model, see Supplemental Data 1. cardboard. The beakers contained no food or water. The mortality rate of cockroaches until the experiment was $<1 \%$.

\section{Conditioning procedure}

Ten minutes before the training, beakers containing cockroaches were transferred from the rearing room to an experimental room. Training was performed in the dark period of the light-dark cycle under white fluorescent light. We have observed that cockroaches learn odors under white light as effectively as they do in the dark (Sato et al. 2006; Matsumoto et al. 2012). The cockroaches were subjected to conditioning trials to associate an odor (CS) with sucrose (US). Rose or orange odor was used as CS and 0.5 M sucrose solution was used as US. Hypodermic syringes (each $1 \mathrm{~mL}$ ) were used to present CS and US stimuli. A small filter paper $(3 \times 3$ $\mathrm{mm}$ ) was attached to the needle of the syringe at $10 \mathrm{~mm}$ from its tip (Fig. 1B). The syringe was filled with sucrose solution. The filter paper attached to the needle was soaked with odor essence (rose or orange). The cockroaches received presentation of a CS for $6 \mathrm{sec}$, and after $3 \mathrm{sec}$, US was presented for $3 \mathrm{sec}$, with a 3-sec overlap to CS presentation (Fig. 1C: paired group). For CS presentation, the filter paper was placed near the midpoint of the length of the antenna. Presence or absence of MER during a period of 3 sec from the CS onset was recorded. For US presentation, a drop of sucrose solution was presented to the antennae and then to the mouth and the cockroach was allowed to drink it. The number of trials and the ITIs were changed according to the purpose of experiments. After training, cockroaches were placed in a rearing room under a reversed light-dark cycle until the retention test.

\section{Retention test}

A memory retention test was performed under white fluorescent light during the dark period. Retention of CS-specific memory was assessed by comparing percentages of MERs to two odors (rose odor and orange odor): one odor was a CS and the other odor was a novel odor not used in training. The order of presentations of the two odors was randomized to avoid sequential effects. The CS and the novel odor were presented for 6 sec each with an interval of $5 \mathrm{~min}$. After the retention test, sucrose solution was applied to the mouth or the antenna and resulting MER was tested. Data for cockroaches that did not show MER to sucrose US were discarded. Cockroaches that did not show response to US were $<0.7 \%$.

\section{Pharmacology}

For injection of drugs, cockroaches were anesthetized with $\mathrm{CO}_{2}$ and then a small hole was made in the head capsule between ocelli by a syringe needle. At $30 \mathrm{~min}$ before the start of training, the cockroaches were each injected with $3 \mu \mathrm{L}$ saline or saline containing 1.25\% DMSO (D-saline), $25 \mathrm{mM}$ cycloheximide (CHX, translation inhibitor, Sigma-Aldrich), $0.5 \mathrm{mM}$ L-NAME (NO synthesis inhibitor, Sigma-Aldrich), or $2.5 \mathrm{mM}$ actinomycin-D (Act-D, transcription inhibitor, Nakarai, Tokyo) into the head hemolymph with a microsyringe according to the method of Matsumoto et al. (2013).

\section{Data analysis}

Occurrence of MER to the test odor was recorded in training and in retention tests. In all experiments, the percentage of MERs was calculated as the number of cockroaches that exhibited MER to the CS divided by the total number of cockroaches studied. Acquisition performance was evaluated by comparing percentage of MERs to the CS with increase in the number of training trials using Cochran's Q test. Retention performance was evaluated by comparing percentages of MERs to the CS and that to the novel odor using McNemar's test. Fisher's exact test was used to compare percentages of MERs in training or the retention test between different groups. In the case of comparison among three or more groups, we constructed generalized linear models (GLMs), assuming a binomial distribution, and the significance of the difference of the effect of conditioning on 
percentage of MER was tested among groups by the likelihood-ratio test (LR test). If there was a significant difference $(<0.05)$, we then compared between the lowest-performance group and each of the other groups by Fisher's exact test, with the $P$-value adjusted for multiple comparisons by Holm's method. All statistical results are described in the figure legends.

\section{Acknowledgments}

This study was supported by Grants-in-Aid for Scientific Research from the Ministry of Education, Science, Culture, Sports and Technology of Japan (No. 24370030, 16H04814, and 16K18586).

\section{References}

Akalal DBG, Yu D, Davis RL. 2010. A late-phase, long-term memory trace forms in the $\gamma$ neurons of Drosophila mushroom bodies after olfactory classical conditioning. I Neurosci 30: 16699-16708.

Awata H, Wakuda R, Ishimaru Y, Matsuoka Y, Terao K, Katata S, Matsumoto Y, Hamanaka Y, Noji S, Mito T, et al. 2016. Roles of OA1 octopamine receptor and Dop1 dopamine receptor in mediating appetitive and aversive reinforcement revealed by RNAi studies. Sci Rep 6: 29696 .

Boeckh J, Ernst KD. 1987. Contribution of single unit analysis in insects to an understanding of olfactory function. J Comp Physiol A 161: 549-565.

Brookshire KH, Warren JM, Ball GG. 1961. Reversal and transfer learning following overtraining in rat and chicken. J Comp Physiol Psychol 54: 98-102.

Cepeda NJ, Pashler H, Vul E, Wixted JT, Rohrer D. 2006. Distributed practice in verbal recall tasks: A review and quantitative synthesis. Psychol Bull 132: $354-380$

Dudai Y. 2012. The restless engram: consolidations never end. Annu Rev Neurosci 35: $227-247$.

Dudai Y, Morris RG. 2013. Memorable trends. Neuron 80: 742-750.

Gerber B, Menzel R. 2000. Contextual modulation of memory consolidation. Learn Mem 7: 151-158.

Gerber B, Wüstenberg D, Schütz A, Menzel R. 1998. Temporal determinants of olfactory long-term retention in honeybee classical conditioning: nonmonotonous effects of the training trial interval. Neurobiol Learn Mem 69: 71-78.

Giurfa M, Sandoz JC. 2012. Invertebrate learning and memory: Fifty years of olfactory conditioning of the proboscis extension response in honeybees. Learn Mem 19: 54-66.

Hellstern F, Malaka R, Hammer M. 1998. Backward inhibitory learning in honeybees: A behavioral analysis of reinforcement processing. Learn Mem 4: 429-444.

Ishida M, Papini MR. 1997. Massed trial overtraining effects on extinction and reversal performance in turtles (Geoclemys reevesii). Quart J Exp Psychol B 50: $1-16$.

Kamin LJ. 1957. The retention of an incompletely learned avoidance response. J Comp Physiol Psychol 50: 457-460.

Kandel ER, Dudai Y, Mayford MR. 2014. The molecular and systems biology of memory. Cell 157: 163-186.

Klein SB, Spear NE. 1970. Forgetting by the rat after intermediate intervals ("Kamin effect") as retrieval failure. J Comp Physiol Psychol 71: 165-170.

Margulies C, Tully T, Dubnau J. 2005. Deconstructing memory in Drosophila. Curr Biol 15: R700-R713.

Marra V, O'Shea M, Benjamin PR, Kemenes I. 2013. Susceptibility of memory consolidation during lapses in recall. Nat Commun 4: 1578 .

Matsumoto Y, Mizunami M. 2002. Temporal determinants of long-term retention of olfactory memory in the cricket Gryllus bimaculatus. J Exp Biol 205: 1429-1437.

Matsumoto Y, Noji S, Mizunami M. 2003. Time course of protein synthesis-dependent phase of olfactory memory in the cricket Gryllus bimaculatus. Zoolog Sci 20: 409-416.

Matsumoto Y, Unoki S, Aonuma H, Mizunami M. 2006. Critical roles of the nitric oxide-cGMP cascade in the formation of cAMP-dependent long-term memory. Learn Mem 13: 35-44.

Matsumoto CS, Matsumoto Y, Watanabe H, Nishino H, Mizunami M. 2012. Context-dependent olfactory learning monitored by activities of salivary neurons in cockroaches. Neurobiol Learn Mem 97: 30-36.

Matsumoto CS, Kuramochi T, Matsumoto Y, Watanabe H, Nishino H, Mizunami M. 2013. Participation of NO signaling in formation of long-term memory in salivary conditioning of the cockroach. Neurosci Lett 541: $4-8$.

Matsumoto Y, Sandoz JC, Devaud JM, Lormant F, Mizunami M, Giurfa M. 2014. Cyclic nucleotide-gated channels, calmodulin, adenylyl cyclase and calcium/calmodulin-dependent kinase II are required for late but not early long-term memory formation in the honey bee. Learn Mem 21: $272-286$.

Matsumoto Y, Matsumoto CS, Wakuda R, Ichihara S, Mizunami M. 2015. Roles of octopamine and dopamine in appetitive and aversive memory acquisition studied in olfactory conditioning of maxillary palpi extension response in crickets. Front Behav Neurosci 9: 230.

Menzel R. 1979. Behavioural access to short-term memory in bees. Nature 281: $368-369$.

Menzel R. 1999. Memory dynamics in the honey bee. J Comp Physiol A 185: $323-340$.

Menzel R, Manz G, Menzel R, Greggers U. 2001. Massed and spaced learning in honeybees: The role of CS, US, the intertrial interval, and the test interval. Learn Mem 8: 198-208.

Naqib F, Sossin WS, Farah CA. 2012. Molecular determinants of the spacing effect. Neural Plast 2012: 581291.

Nishino H, Iwasaki M, Mizunami M. 2011. Pheromone detection by a pheromone emitter: A small, sex pheromone-specific processing system in the female American cockroach. Chem Senses 36: 261-270.

Nishino H, Iwasaki M, Yasuyama K, Hongo H, Watanabe H, Mizunami M. 2012. Visual and olfactory input segregation in the mushroom body calyces in a basal neopteran, the American cockroach. Arthropods Struct Develop 41: 3-16.

Nishino H, Watanabe H, Kamimura I, Yokohari F, Mizunami M. 2015. Coarse topographic organization of pheromone-sensitive afferents from different antennal surfaces in the American cockroach. Neurosci Lett 595: 35-40.

Pagani MR, Oishi K, Gelb BD, Zhong Y. 2009. The phosphatase SHP2 regulates the spacing effect for long-term memory induction. Cell 139: 186-198.

Philips GT, Tzvetkova EI, Carew TJ. 2007. Transient mitogen-activated protein kinase activation is confined to a narrow temporal window required for the induction of two-trial long-term memory in Aplysia. J Neurosci 27: 13701-13705.

Riege WH, Cherkin A. 1971. One-trial learning and biphasic time course of performance in the goldfish. Science 172: 966-968.

Rosenzweig MR, Bennett EL, Colombo PJ, Lee DW, Serrano PA. 1993. Short-term, intermediate-term, and long-term memories. Behav Brain Res 57: 193-198.

Sakura M, Mizunami M. 2001. Olfactory learning and memory in the cockroach Periplaneta americana. Zoolog Sci 18: 21-28.

Sakura M, Okada R, Mizunami M. 2002. Olfactory discrimination of structurally similar alcohols by cockroaches. J Comp Physiol A 188: 787-797.

Sanders GD, Barlow JJ. 1971. Variations in retention performance during long term memory formation. Nature 232: 203-204.

Sato C, Matsumoto Y, Sakura M, Mizunami M. 2006. Contextual olfactory learning in cockroaches. Neuroreport 17: 553-557.

Sunsay C, Bouton ME. 2008. Analysis of a trial-spacing effect with relatively long intertrial intervals. Learn Behav 36: 104-115.

Sutton MA, Ide J, Masters SE, Carew TJ. 2002. Interaction between amount and pattern of training in the induction of intermediate- and long-term memory for sensitization in Aplysia. Learn Mem 9: 29-40.

Tiunova AA, Anokhin KV, Rose SP. 1998. Two critical periods of protein and glycoprotein synthesis in memory consolidation for visual categorization learning in chicks. Learn Mem 4: 401-410.

Tully T, Preat T, Boynton SC, Del Vecchio M. 1994. Genetic dissection of consolidated memory in Drosophila. Cell 79: 35-47.

Watanabe H, Mizunami M. 2006. Classical conditioning of activities of salivary neurons in an insect. I Exp Biol 209: 766-779.

Watanabe H, Mizunami M. 2007. Pavlov's cockroach: Classical conditioning of salivation in an insect. PLoS One 6: e529.

Watanabe H, Kobayashi Y, Sakura M, Matsumoto Y, Mizunami M. 2003. Classical olfactory conditioning in the cockroach Periplaneta americana. Zoolog Sci 20: 1447-1454.

Watanabe H, Sato C, Kuramochi T, Nishino H, Mizunami M. 2008. Salivary conditioning with antennal gustatory unconditioned stimulus in an insect. Neurobiol Learn Mem 90: 245-254.

Watanabe H, Nishino H, Nishikawa M, Mizunami M, Yokohari F. 2010. Complete mapping of glomeruli based on sensory nerve branching pattern in the primary olfactory center of the cockroach Periplaneta americana. J Comp Neurol 518: 3907-3930.

Watanabe H, Matsumoto SC, Nishino H, Mizunami M. 2011. Critical roles of mecamylamine-sensitive mushroom body neurons in insect olfactory learning. Neurobiol Learn Mem 95: 1-13.

Zhang Y, Liu RY, Heberton GA, Smolen P, Baxter DA, Cleary LJ, Byrne JH. 2012. Computational design of enhanced learning protocols. Nat Neurosci 15: 294-297.

Received July 16, 2016; accepted in revised form August 17, 2016. 


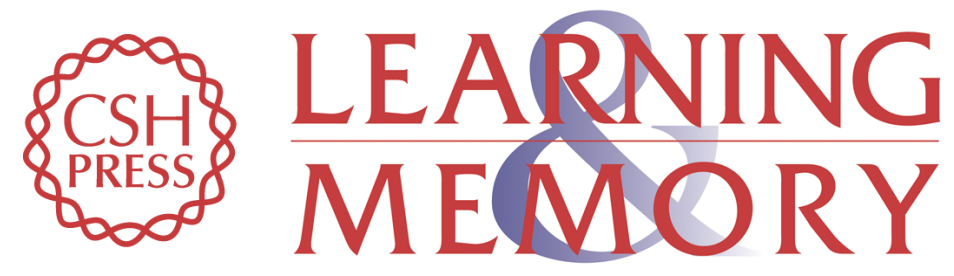

\section{Interaction of inhibitory and facilitatory effects of conditioning trials on long-term memory formation}

Shouhei Hosono, Yukihisa Matsumoto and Makoto Mizunami

Learn. Mem. 2016, 23:

Access the most recent version at doi:10.1101/Im.043513.116

\section{Supplemental http://learnmem.cshlp.org/content/suppl/2016/11/09/23.12.669.DC1 \\ Material http://learnmem.cshlp.org/content/suppl/2016/11/29/23.12.669.DC2}

References This article cites 50 articles, 13 of which can be accessed free at:

http://learnmem.cshlp.org/content/23/12/669.full.html\#ref-list-1

Creative This article is distributed exclusively by Cold Spring Harbor Laboratory Press for the

Commons first 12 months after the full-issue publication date (see

License http://learnmem.cshlp.org/site/misc/terms.xhtml). After 12 months, it is available under a Creative Commons License (Attribution-NonCommercial 4.0 International), as described at http://creativecommons.org/licenses/by-nc/4.0/.

Email Alerting Receive free email alerts when new articles cite this article - sign up in the box at the Service top right corner of the article or click here. 